\title{
WORKSHOP PENGAYAAN MATERI DAN PELATIHAN PENYELESAIAN SOAL-SOAL OLIMPIADE IPA BAGI GURU MIM TEGALAMPEL, KLATEN
}

\author{
Muhamad Taufik Hidayat ${ }^{1}$, Nuqthy Faiziyah ${ }^{2}$, Hendiawan Setiyoso ${ }^{3}$, \\ Windy Cahyuningsih ${ }^{4}$, Dewi Anarani ${ }^{5}$, Rizki Yakaria Novandi ${ }^{6}$ \\ ${ }^{1}$ Pendidikan Guru Sekolah Dasar, Universitas Muhammadiyah Surakarta \\ email: mt.hidayat@ums.ac.id \\ ${ }^{2}$ Pendidikan Matematika, Universitas Muhammadiyah Surakarta \\ email: nuqthy.faiziyah@ums.ac.id \\ ${ }^{3}$ Pendidikan Guru Sekolah Dasar, Universitas Muhammadiyah Surakarta \\ email: hendiiyoso@gmail.com \\ ${ }^{4}$ Pendidikan Guru Sekolah Dasar, Universitas Muhammadiyah Surakarta \\ email: windyycahyyu@gmail.com \\ ${ }^{5}$ Pendidikan Guru Sekolah Dasar, Universitas Muhammadiyah Surakarta \\ email: dewianarani@gmail.com \\ ${ }^{6}$ Teknik Mesin, Universitas Muhammadiyah Surakarta \\ email: d200120171@student.ums.ac.id
}

\begin{abstract}
MIM Tegalampel is one of primary school in Klaten Regency which is pioneering the special program of the Science Olympiad (OSN). The purpose of this community service program is to provide knowledge and skills to teachers of MIM Tegalampel so they can identify the types of OSN material, apply several mastery strategies for OSN material, as well as solve OSN problems quickly and accurately. The method used is the method of enrichment, demonstration and try out. The evaluation of the implementation of this community service consisted of an initial evaluation in the form of a pre-test, the final evaluation in the form of a post-test, as well as an evaluation of the implementation. Based on the result of the workshop for teachers of MIM Tegalampel, it can be concluded that in general the participants considered the workshop scheduling to be appropriate, time sharing was appropriate, the balance between theory and practice was also appropriate. Participants considered most of the expectations and objectives of the workshop had been fulfilled. The evaluation result showed that participants had increased skills in identifying the types of OSN material. There was also an increase in the skills of participants in completing OSN problems. In addition, participants can apply several mastery strategies for OSN material.
\end{abstract}

Keywords: science olympiad; science; primary school

\section{ABSTRAK}

MIM Tegalampel merupakan salah satu sekolah dasar di Kabupaten Klaten yang tengah merintis program unggulan Olimpiade Sains Nasional (OSN). Tujuan dari program pengabdian ini adalah memberikan pengetahuan dan ketrampilan pada guruguru MIM Tegalampel agar dapat mengidentifikasi jenis-jenis materi OSN IPA SD, menerapkan beberapa strategi penguasaan materi OSN IPA SD dan menyelesaikan 
soal-soal OSN IPA SD dengan cepat dan tepat. Metode kegiatan yang dipakai adalah metode pengayaan, demonstrasi dan try out. Evaluasi pelaksanaan kegiatan pengabdian ini terdiri dari evaluasi awal berupa pre-test, evaluasi akhir berupa posttest, serta evaluasi terhadap pelaksanaan. Berdasarkan hasil pelaksanaan workshop pengayaan materi dan penyelesaian soal-soal OSN IPA SD bagi guru-guru MIM Tegalampel, maka dapat disimpulkan bahwa secara umum peserta menganggap penjadwalan workshop sudah tepat, pembagian waktu sudah sesuai, keseimbangan antara teori dan praktik juga sudah sesuai. Peserta menganggap sebagian besar harapan dan tujuan dari workshop sudah terpenuhi. Hasil evaluasi menunjukkan bahwa peserta terjadi peningkatan ketrampilan mengidentifikasi jenis-jenis materi OSN IPA $S D$. Terjadi pula peningkatan pada keterampilan peserta menyelesaikan soal-soal OSN IPA SD. Selain itu peserta dapat menerapkan beberapa strategi penguasaan materi OSN IPA SD.

Kata Kunci: olimpiade sains; IPA; sekolah dasar

\section{PENDAHULUAN}

Olimpiade Sains Nasional (OSN) adalah Program kompetisi dalam ranah sains untuk siswa-siswa pada jenjang Sekolah Dasar (SD). OSN diadakan setahun sekali di kota yang berbeda-beda (Muliani, Noviati, \& Fajriani, 2018; Susanto, Sembiring, \& Ekowati, 2016). Program ini diselenggarakan untuk memotivasi para Siswa dan guru guna mencapai prestasi terbaik, sekaligus meningkatkan kualitas pendidikan di daerah masing-masing. Pelaksanaan OSN secara rutin akan mempunyai dampak positif pada pelaksanaan proses pembelajaran sehingga menjadi lebih inovatif. Siswa akan memiliki kesempatan untuk mengembangkan seluruh aspek kepribadian dan kemampuan melalui pembelajaran yang efektif, kreatif dan menyenangkan.

Materi OSN SD pada hakekatnya berasal dari kurikulum yang berlaku. Untuk sains IPA materi yang diujikan adalah materi IPA biologi dan materi IPA fisika dengan tingkat kesulitan yang cukup tinggi untuk ukuran siswa SD. Hal ini dikarenakan materi OSN menuntut siswa untuk berfikir tingkat tinggi (high order thinking skill). Berfikir tingkat tinggi meliputi kemampuan menganalisis, mengevaluasi, serta mensintesis.

Madrasah Ibtidaiyah Muhammadiyah (MIM) Tegalampel merupakan salah satu sekolah tingkat dasar Kabupaten Klaten. MIM Tegalampel tengah berkembang menjadi salah satu SD yang unggul. Potensi yang besar dari MIM Tegalampel tersebut perlu dikelola dan dikembangkan secara baik. Berdasarkan hasil program pengambdian sebelumnya MIM Tegalampel telah berhasil menyusun program kerja OSN sebagai program unggulan (Hidayat, Faiziyah, Listiawati, Rini, \& Surahmat, 2019). Salah satu bagian dari program kerja tersebut adalah pembinaan bibit-bibit peserta OSN MIM Tegalampel. Berdasarkan program kerja OSN MIM Tegalampel pembina calon peserta OSN MIM Tegalampel merupakan guru-guru dari sekolah tersebut. Guru MIM Tegalampel yang berjumlah kurang dari 20 orang berlatarbelakang pendidikan yang berbeda-beda. Bagi guru yang berlatarbelakang non pendidikan IPA tentu memiliki kesulitan yang lebih tinggi dalam menguasai materi OSN serta mengajarkannya. Oleh karena itu perlu adanya upaya untuk memberikan 
pengayaan materi OSN SD. Selain itu juga diperlukan adanya pelatihan dalam memecahkan soal OSN SD.

Sebagai salah satu lembaga pendidikan yang mendidik calon tenaga edukatif, Universitas Muhammadiyah Surakarta perlu berperan serta dalam menumbuhkembangkan potensi yang dimiliki oleh siswa dalam OSN (Rasyid, 2005). Salah satu program yang perlu dilakukan adalah pelatihan pengerjaan soal-soal olimpiade IPA dan pengayaan materinya bagi guru di MIM Tegalampel, Klaten yang tengah merintis program unggulan OSN SD.

Dari analisis di atas pada dasarnya baik guru maupun siswa tidak akan mudah menyelesaikan soal-soal olimpiade jika tidak pernah belajar untuk memecahkan masalah yang ada. Siswa membutuhkan bantuan yang cukup. Jika bantuan itu terlalu sedikit, siswa akan mengalami kesulitan yang cukup besar. Sebaliknya jika bantuan tersebut terlalu banyak, maka para siswa akan memperoleh sedikit pengetahuan tentang pemecahan masalah tersebut. Oleh karena itu guru harus memberikan bantuan yang sesuai, sehingga siswa dapat menemukan ide awal untuk menyelesaikan masalah.

Dari latar belakang di atas, rumusan masalah yang dapat ditarik adalah kurangnya pengetahuan dan ketrampilan guru-guru MIM Tegalampel dalam memecahkan soal-soal OSN IPA SD. Tujuan dari program pengabdian ini adalah memberikan pengetahuan dan ketrampilan pada guru-guru MIM Tegalampel agar dapat mengidentifikasi jenis-jenis materi OSN IPA SD, menerapkan beberapa strategi penguasaan materi OSN IPA SD dan menyelesaikan soal-soal OSN IPA SD dengan cepat dan tepat.

Beberapa manfaat yang diharapkan setelah berlangsungnya kegiatan pelatihan ini adalah: (1) Meningkatkan kualitas pendidikan MIM Tegalampel khususnya dan sekolah dasar Karangdowo pada umumnya. (2) Mendukung suksesnya program unggulan MIM Tegalampel dalam bidang OSN. (3) Terjalinnya kerjasama yang saling menguntungkan antara sekolah dengan Universitas Muhammadiyah Surakarta dalam rangka peningkatkan profesionalisme guru.

\section{METODE PELAKSANAAN}

Khalayak sasaran kegiatan ini adalah guru-guru MIM Tegalampel sebagai pembina OSN sejumlah 11 orang. Guru-guru sasaran tersebut telah ditunjuk oleh kepala MIM Tegalampel pada tahun sebelumnya untuk menjadi pembina OSN. Kemudian untuk menjawab dua pertanyaan pada perumusan masalah, maka ditempuh langkah-langkah sebagai berikut: (1) Tahap pertama, peserta diberikan pre-test soal OSN IPA yang dikerjakan secara berkelompok. (2) Hasil pre-test dievaluasi. (3) Peserta diingatkan kembali materi OSN IPA serta strategi umum memecahkannya. (4) Peserta diajak membahas beberapa soal pilihan OSN IPA. (5) Peserta diberikan post-test OSN IPA. (6) Evaluasi hasil post-test apakah ada peningkatan dari pre-test apa tidak

Metode kegiatan yang dipakai adalah metode pengayaan,demonstrasi dan try out. (1) Pengayaan adalah memberikan materi-materi OSN IPA yang 
baru kepada peserta sehingga wawasan mereka bertambah. (2) Demonstrasi dilakukan untuk menguji coba beberapa strategi-strategi dalam memecahkan soal OSN IPA. (3) Try out dilakukan untuk melatih peserta dalam menjawab soal-soal OSN IPA serta mengetahui situasi dalam pengerjaan OSN IPA.

Evaluasi pelaksanaan kegiatan pengabdian ini dirancang sebagai berikut: (1) Evaluasi awal berupa pre-test yang berguna untuk menggali kemampuan awal sebagai pijakan untuk menentukan materi-materi mana yang harus diberikan. Pre test berupa soal olimpiade IPA SD pilihan ganda dan esai singkat. (2) Evaluasi akhir berupa post-test yang berguna untuk melihat tingkat kemajuan setelah peserta diberikan pengayaan maupun pelatihan. Post test juga berupa soal olimpiade IPA SD pilihan ganda dan esai singkat. (3) Evaluasi terhadap pelaksanaan dilakukan dengan memberikan angket, yang akan mengukur tingkat keberhasilan dari pelaksanaan kegiatan ini.

Tabel 1

Sesi Program

\begin{tabular}{|c|c|c|}
\hline Sesi & Metode & Instrumen Evaluasi \\
\hline Pre test Soal OSN IPA (Tim) & Try Out & $\begin{array}{l}\text { Soal OSN IPA dan kunci } \\
\text { jawaban }\end{array}$ \\
\hline Materi OSN IPA + Strategi & $\begin{array}{l}\text { Pengayaan dan } \\
\text { demonstrasi }\end{array}$ & $\begin{array}{l}\text { Lembar pengamatan } \\
\text { dan daftar produk }\end{array}$ \\
\hline $\begin{array}{l}\text { Pembahasan soal pilihan } \\
\text { OSN IPA }\end{array}$ & Pengayaan & Lembar pengamatan \\
\hline $\begin{array}{l}\text { Post test Soal OSN IPA } \\
\text { (Tim) }\end{array}$ & Try Out & $\begin{array}{l}\text { Soal OSN IPA dan kunci } \\
\text { jawaban }\end{array}$ \\
\hline
\end{tabular}

\section{HASIL DAN PEMBAHASAN}

\section{Pre test Soal OSN (Tim)}

Program pengabdian ini diawali dengan sambutan-sambutan. Sambutan yang pertama dari Kepala MIM Tegalampel. Kepala MIM Tegalampil sangat antusias dengan adanya program pengabdian lanjutan di tempat mereka. Kepala dan guru MIM Tegalampel telah melakukan sebagian follow up dari program pengabdian sebelumnya.

Sesi ini dibuka oleh pemateri dengan sedikit mengulang kembali hasil program pengabdian sebelumnya, yaitu membuat program kerja jangka pendek dan jangan panjang OSN MIM Tegalampel. Kemudian pemateri bersama peserta membuat kontrak kegiatan berupa sesuatu yang harus dilakukan dan tidak boleh dilakukan serta hukuman. Selanjutnya pemateri memberikan pre-test yaitu berupa soal OSN IPA berupa pilihan ganda dan esai singkat. Soal OSN tersebut dikerjakan secara bersamasama (tim pembina OSN IPA). Agar penyelesaian soal lebih cepat peserta direkomendasikan untuk membagi soal tersebut sesuai pembagian materi yang telah mereka sepakati. Misalkan peserta A yang mendapatkan tugas membina siswa materi listrik maka diharapkan mengerjakan soal tentang 
listrik. Sedangkan peserta B yang mendapat tugas membina siswa materi interaksi makhluk hidup maka diharapkan mengerjakan soal interaksi makhluk hidup. Peseta boleh membuka buku, browsing, maupun memakai kalkulator.

Hasil dari kerja kelompok tersebut dievaluasi oleh pemateri. Aspek yang dievaluasi adalah (1) Berapa soal yang telah diisi dengan yakin? (2) Apakah sudah dilakukan pembagian dengan baik? (3) Berapa banyak jenis materi yang berhasil diidentifikasi? (4) Berapa banyak jawaban yang benar? (5) Bagaimana caranya menyelesaikan soal tersebut?

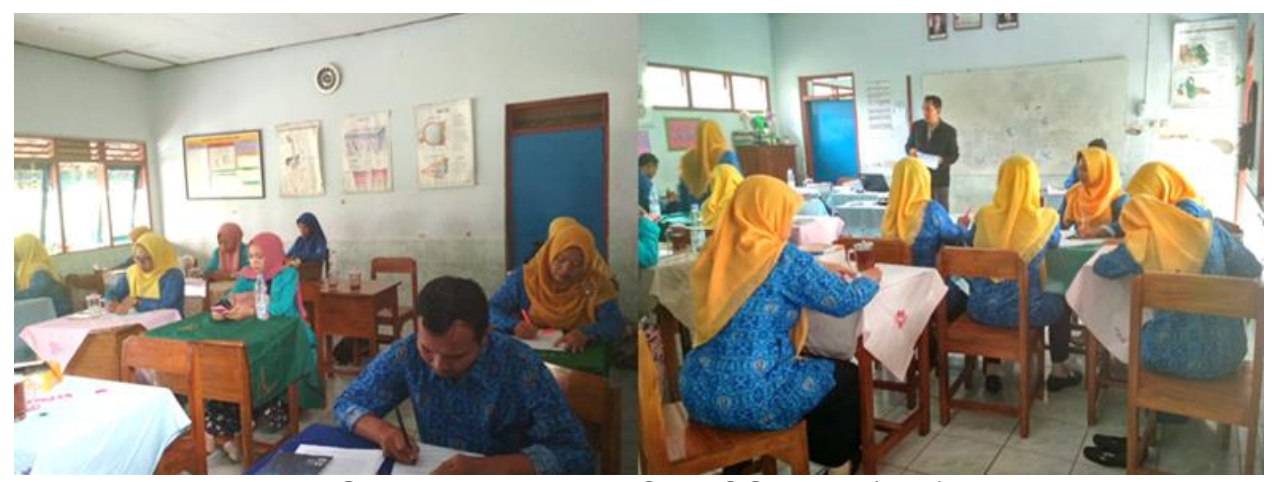

Gambar 1. Pre test Soal OSN IPA (Tim)

\section{Materi OSN IPA dan Strategi}

Sesi ini diawali dengan menyebutkan kembali materi-materi OSN IPA SD. Materi tersebut antara lain: Listrik, Magnet, gelombang, mekanika, Wujud benda, optik, suhu-panas, energy, atom, isu-isu umum, bumi dan tata surya, interaksi makhluk hidup, mekanisme makhluk hidup, klasifikasi makhluk hidup, serta metode ilmilah. Selanjutnya pemateri memutarkan trailer film lascar pelangi sebagai selingan dan motivasi.

Selanjutnya secara umum pemateri memberitahukan kepada peserta bahwa strategi menguasai materi-materi OSN tersebut diatas yaitu dengan 3 hal: memahami, menghafalkan, dan berlatih. Memahami dalam hal ini bukan berarti ketrampilan kognitif tingkat dua belaka tetapi juga ketrampilan kognitif tingkat tinggi (high order thinking skill). Selain itu beberapa materi khususnya materi biologi juga perlu dihafalkan. Sementara itu materi-materi fisika perlu banyak dilatih dalam pemecahan soalnya.

Pemateri kemudian menampilkan beberapa sumber belajar OSN IPA. Sumber belajar yang pertama yaitu buku-buku OSN. Buku-buku ini berisi materi soal serta pembahasannya. Sumber belajar lainnya yaitu berupa video materi IPA maupun video pembahasan di youtube.

Selanjutnya pemateri membagi peserta menjadi dua kelompok. Kelompok A diminta untuk menghafal materi terpilih yang ada dibuku OSN secara konvensional. Sedangkan kelompok B diminta untuk menghafalkan 
materi terpilih dengan empat strategi. Pertama mencatat ulang dengan mind mapping. Kedua, menghafal dengan jembatan keledai atau menomenic. Ketiga, peserta diminta membaca ditempat yang nyaman. Keempat, peserta diminta mempresentasikan mind mapping dan mnemonic kepada anggota kelompoknya. Setelah itu diuji hafalan dari kelompok $\mathrm{A}$ dan kelompok $\mathrm{B}$. Metode mind mapping dipilih karena terbukti meningkatkan prestasi belajar IPA (Purnamiati, 2017; Rahmawati \& Budiningsih, 2019; Safitri, 2016; Widiana \& Jampel, 2018).

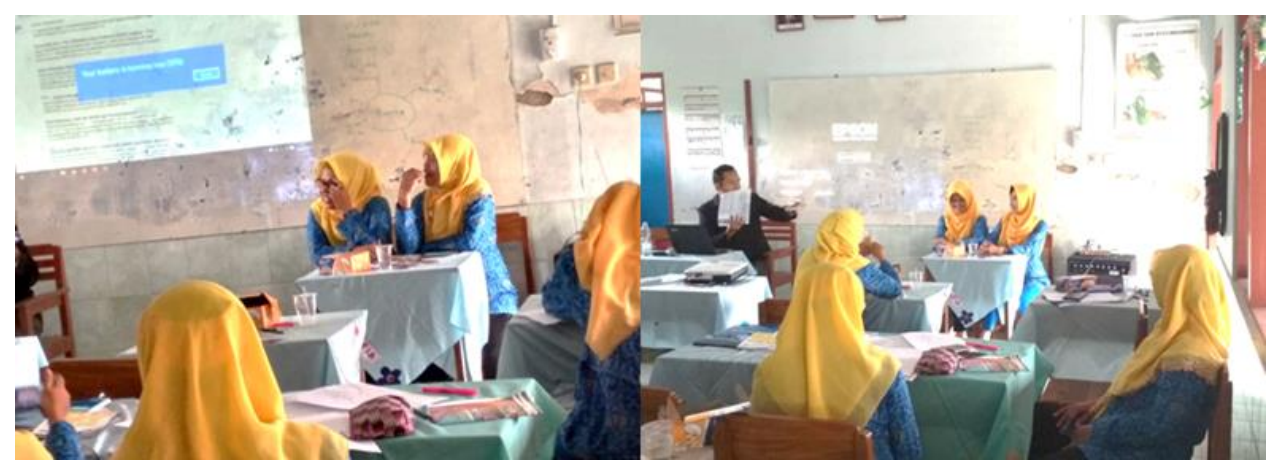

Gambar 2. Materi OSN IPA dan Strategi

\section{Pembahasan soal pilihan OSN IPA}

Pada sesi ini pemateri mempresentasikan beberapa soal pilihan OSN dan cara mengerjakannya. Pemateri mengulas mengapa jawaban tersebut benar dan mengapa jawaban yang lain salah. Peserta cukup antusias dalam sesi ini sehingga muncul beberapa pertanyaan dari peserta. Beberapa peserta ternyata mengalami miskonsepsi dalam memahami beberapa materi OSN IPA. Sebagai besar contoh sebagian peserta menganggap dua benda bermassa berbeda yang mengalami gerak jatuh bebas akan jatuh dengan kecepatan yang berbeda.

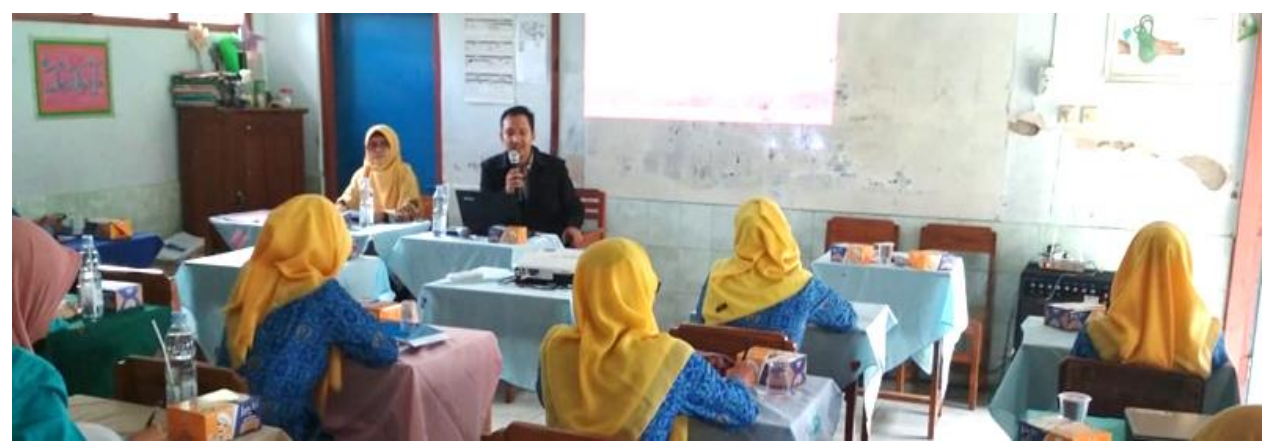

Gambar 3. Pembahasan soal pilihan OSN IPA 


\section{Post test Soal OSN IPA (Tim)}

Pada sesi terakhir ini pemateri memberikan post-test yaitu berupa soal OSN IPA seperti pada saat pre-test. Soal OSN tersebut juga dikerjakan secara bersama-sama (tim pembina OSN IPA). Hasil dari kerja kelompok tersebut dievaluasi kembali oleh pemateri dengan aspek-aspek yang sama pada saat pre-test.

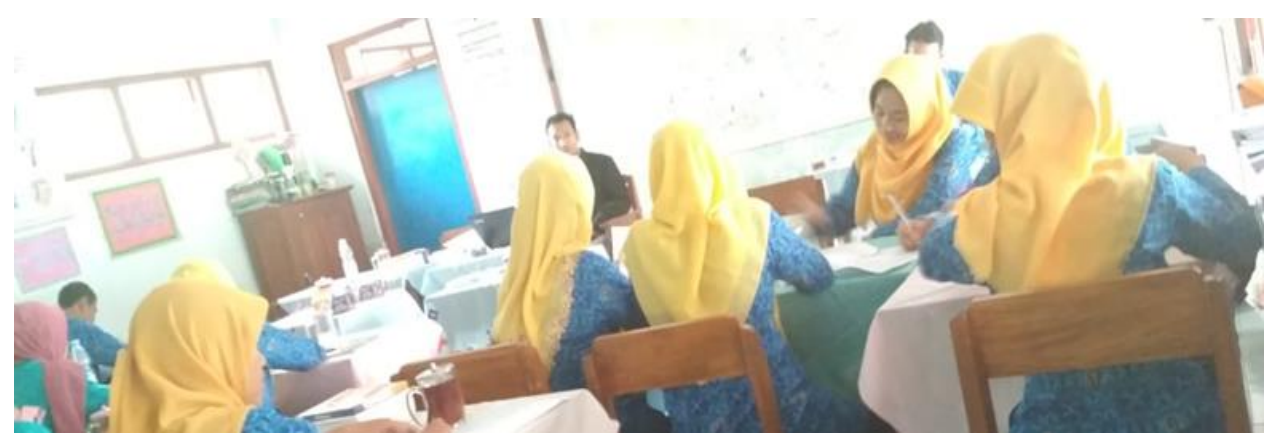

Gambar 4. Post test Soal OSN IPA (Tim)

\section{Evaluasi}

Secara umum program pengabdian ini mendapatkan respon yang positif dari peserta. Respon positif ini diukur dengan indikator jadwal dan waktu kegiatan, metode yang digunakan, isi workshop, harapan yang terpenuhi, dan pemateri. Saran dari peserta diantaranya dengan memberikan soal OSN yang lebih beragam.

Berdasarkan hasil pre-test dan post-test diketahui bahwa (1) kesesuian pembagian soal meningkat (2) jenis materi yang berhasil diidentifikasi meningkat (3) jawaban yang benar menurun. Hal ini dikarenakan tingkat kesulitan soal post-test lebih tinggi dari soal pre-test.

\section{KESIMPULAN}

Berdasarkan hasil pelaksanaan workshop pengayaan materi dan penyelesaian soal-soal OSN IPA SD bagi guru-guru MIM Tegalampel, maka dapat disimpulkan bahwa secara umum peserta menganggap penjadwalan workshop sudah tepat, pembagian waktu sudah sesuai, keseimbangan antara teori dan praktik juga sudah sesuai. Peserta menganggap sebagian besar harapan dan tujuan dari workshop sudah terpenuhi.

Hasil evaluasi menunjukkan bahwa peserta terjadi peningkatan ketrampilan mengidentifikasi jenis-jenis materi OSN IPA SD. Terjadi pula peningkatan pada ketrampilan peserta menyelesaikan soal-soal OSN IPA SD. Selain itu peserta dapat menerapkan beberapa strategi penguasaan materi OSN IPA SD. 


\section{DAFTAR RUJUKAN}

Hidayat, M. T., Faiziyah, N., Listiawati, V., Rini, I. F., \& Surahmat. (2019). Workshop Penyusunan Program Unggulan OSN di Madrasah Ibtidaiyah Muhammadiyah Tegalampel, Klaten. Jurnal Pengabdian Pada Masyarakat, 4(1).

Muliani, F., Noviati, D., \& Fajriani. (2018). Pembinaan Peningkatan Mutu Pendidikan Bidang Olimpiade Sains bagi Guru SD Kota Langsa Provinsi Aceh. Jurnal ABDIMAS Unmer Malang, 3(2), 9-13.

Purnamiati, G. A. K. D. ; dkk. (2017). Pengaruh Penerapan Model Pembelajaran Kooperatif Tipe Mind Mapping Terhadap Kreativitas dan Prestasi Belajar IPA Siswa Kelas VI SD No. 3 Benoa Kabupaten Badung. PENDASI: Jurnal Pendidikan Dasar Indonesia.

Rahmawati, M. M. E., \& Budiningsih, C. A. (2019). Pengaruh Mind Mapping dan Gaya Belajar terhadap Pemahaman Konsep Siswa Pada Pembelajaran IPA. Jurnal Inovasi Teknologi Pendidikan. https://doi.org/10.21831/tp.v1i2.2524

Rasyid, R. (2005). Peranan Perguruan Tinggi dalam Meningkatkan Kualitas Olimpiade Sains Nasional Tingkat Sekolah Dasar. Seminar Nasional Penelitian, Pendidikan Dan Penerapan MIPA, F412-F418. Yogyakarta: FMIPA UNY.

Safitri, D. (2016). Penerapan Metode Mind Mapping Untuk Meningkatkan Minat Dan Hasil Belajar Ipa Siswa Kelas V SD N Balangan 1. Pendidikan Guru Sekolah Dasar.

Susanto, G. N., Sembiring, S., \& Ekowati, C. N. (2016). Pembinaan Guru Sebagai Dasar Peningkatan Prestasi Siswa SD dalam Ajang Kompetisi OSN SD IPA Tingkat Nasional. Seminar Nasional Hasil-Hasil Pengabdian Kepada Masyarakat, 112-123. Bandar Lampung: LPPM Universitas Lampung.

Widiana, I. W., \& Jampel, I. N. (2018). Improving Students' Creative Thinking and Achievement through The Implementation of Multiple Intelligence Approach with Mind Mapping. International Journal of Evaluation and Research in Education (IJERE). https://doi.org/10.11591/ijere.v5i3.4546 